Brit. J. prev. soc. Med. (1976), 30, 132-137

\title{
Anencephalus in Scotland 1961-72
}

\author{
JEAN FEDRICK \\ Unit of Clinical Epidemiology, Department of the Regius Professor of Medicine, University of Oxford
}

\begin{abstract}
Fedrick, J. (1976). British Journal of Preventive and Social Medicine, 30, 132-137. Anencephalus in Scotland 1961-72. Data relating to the incidence of anencephalus for the 12-year period 1961-72 were abstracted from the Statistical Reviews of the Registrar General for Scotland. It was shown that considerable geographical variation is still apparent with the highlands having, in general, the lower incidences. In comparison with the earlier study of Edwards (1958), there were some changes: the incidence in the areas to the west had increased and that in those to the east decreased. During the 12-year period there was an overall decline in the incidence of the lesion; this was most marked in births to women under 20 years, and to those of social classes III, IV, and V. The decline was least apparent for births to women of high social class and the unmarried. It was shown that there was little seasonal variation in the time of delivery, but that even when the trend had been taken into account the yearly fluctuation was significantly different from that expected, with an excess of cases in 1961 and 1971.
\end{abstract}

Edwards (1958) published a detailed analysis of stillbirths and infant deaths associated with malformations of the central nervous system in Scotland.

The purpose of the present paper is to repeat Edwards's original analyses, but for a later period (1961-72) and only for the malformation anencephalus. The study of the other two lesions would be of limited value since his case ascertainment was confined to those infants stillborn or dying during infancy, and a considerable and probably variable proportion of cases of both spina bifida and hydrocephalus survive this period.

\section{MATERIAL AND MethodS}

All data pertaining to anencephalus, whether as a cause of stillbirth or of infant death, were abstracted from the Annual Reports of the Registrar General for Scotland together with the corresponding figures for the whole population of live and stillbirths. Incidences were calculated in the normal way and presented as rates per 1000 total births.

\section{RESULTS}

Out of 1162939 total births which were delivered during the 12-year period, 3246 were stated to be anencephalics giving a rate of $2 \cdot 79$. Of these 295 $(9 \cdot 1 \%)$ were registered as livebirths.

\section{REgIONAL VARIATION}

One of the main findings in Edwards's paper (Edwards, 1958) was a marked variation in incidence within Scotland, with highest rates in the lowlands and lowest rates in the highlands.

Using the 12-year data on stillbirths with anencephalus (Fig. 1), it can be seen that again $N$ there is considerable variation within counties. The highest incidences were found in the south of $O$ the country especially in the belt from the Clyde to $\mathrm{W}$ the Firth of Forth. Seven ( $21 \%$ ) of the 33 counties, had incidences that were significantly different (at the $5 \%$ level) from the remainder of Scotland $\$$ (Aberdeen, Caithness, Midlothian, Perth, and Zet-? land being significantly lower, Lanark and Stirling higher).

To examine the change in incidence from the

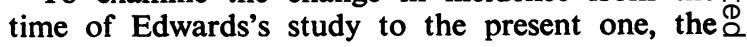



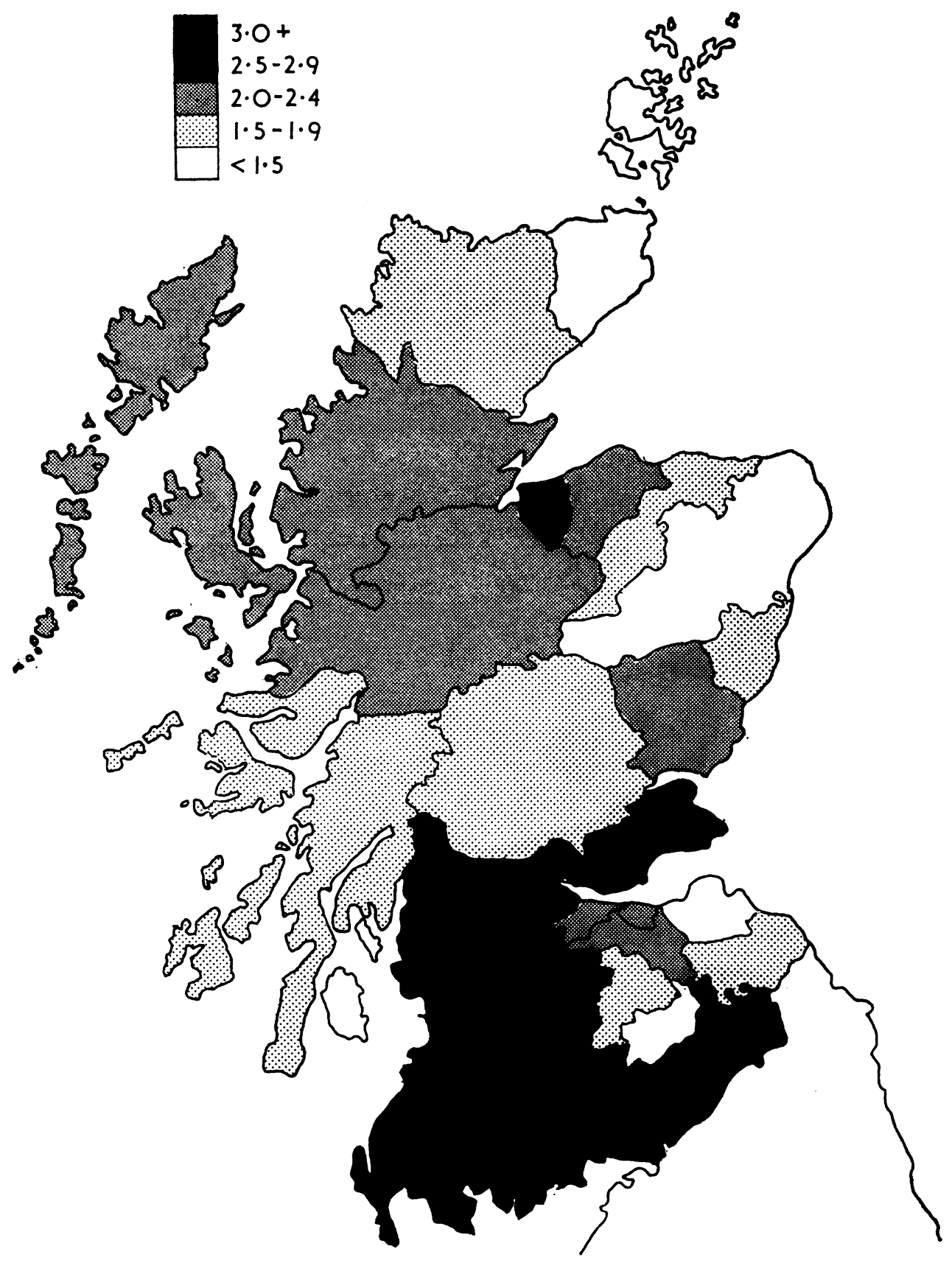

FIG. 1. Incidence of stillbirths with anencephalus in Scotland 1961-1972. 
counties have been grouped as in the former study. As can be seen in Fig. 2 there has been a marked variation in that the incidence appears to have decreased in a band of areas to the east of the country and increased to the west.

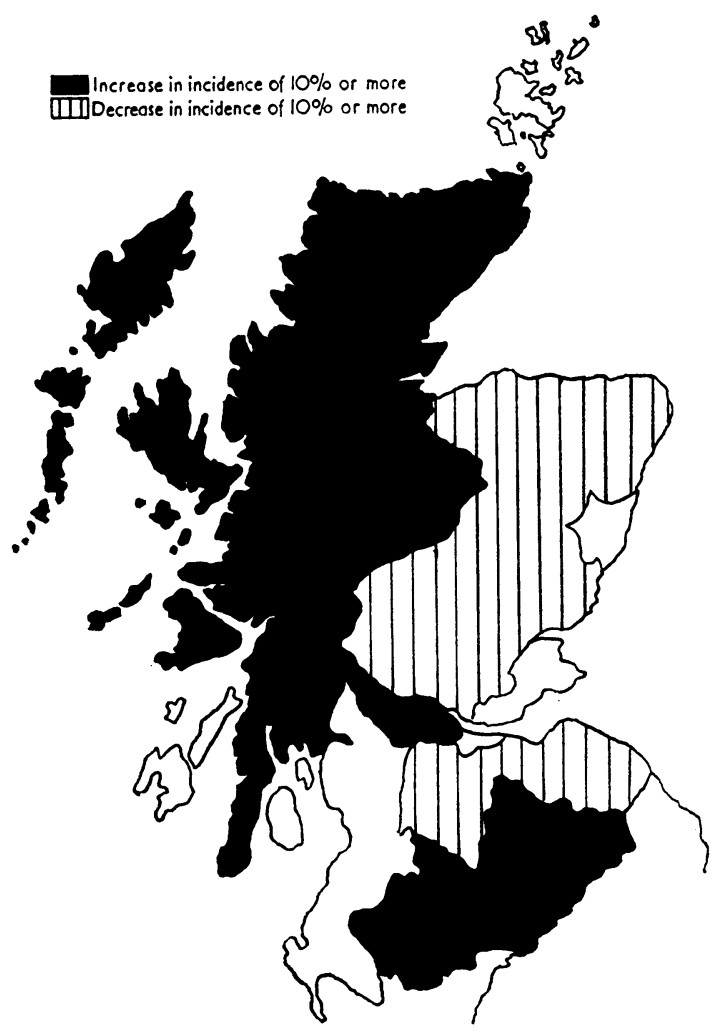

Fig. 2. Changes in the incidence of stillbirths with anencephalus in Scotland between the periods 1950-56 and 1960-72.

\section{Urban versus Rural Areas}

Edwards (1958) developed a method of assessing whether there had been any increase in urban compared with rural rates after taking the general regional variation into account. To do this he compared the incidence of the lesion among infants delivered to mothers resident in an urban area with that pertaining in the contiguous rural areas; he found that the weighted mean urban/rural ratio for anencephalus was $1 \cdot 0$-that is, that there was no difference between the rates in urban and rural areas once the general geographical variation had been taken into acccount.

A similar analysis of the present data produced a weighted mean ratio equal to $1 \cdot 12$ (significantly different from $1 \cdot 0, P<0.05)$. Edwards, however, suggested that large cities and ports were atypical because they were likely to contain a large proportion of immigrants. If they are excluded from the analysis the urban effect becomes slightly greater (mean ratio $=1 \cdot 17$ ), but is no longer statistically significant $(0 \cdot 1>\mathrm{P}>0.05)$.

\section{Social Class}

Edwards's study was one of the first to show the marked trend in incidence with social class: a result that has been confirmed in Belfast (Elwood, 1970) and in the United Kingdom (Butler and Alberman, 1969). The more recent Scottish data presented here (Table I) show the same effect, with the incidence among births to women in social class $\mathrm{V}$ some three times that among deliveries to women in social class $\mathrm{I}$.

TABLE I

INCIDENCE OF LIVE AND STILLBIRTHS WITH ANENCEPHALUS BY PATERNAL SOCIAL CLASS (LEGITIMATE BIRTHS ONLY)

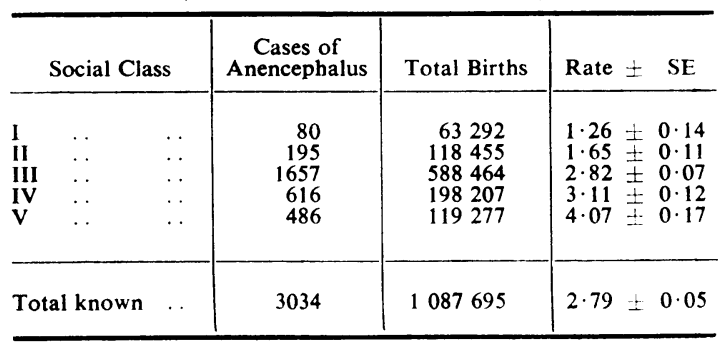

\section{LEGITIMACY}

Edwards noted that in both his series and the previous one of Record and McKeown (1949) in Birmingham there were actually fewer illegitimate anencephalics than expected. This, he noted, was especially striking since the unmarried mother was more likely to have come from a lower social class environment. From 1961-72, though, the rate of anencephalus was almost identical in legitimate $(2 \cdot 79)$ and illegitimate $(2 \cdot 82)$ births.

\section{PARITY}

Edwards showed that an infant born to a primipara was almost $40 \%$ more likely to be an anencephalic than was a second-born infant. The more recent data (Table II) show that the contrast between the incidences is now smaller with only $22 \%$ increase in incidence in first compared with second births. Nevertheless, the effect is still highly significant.

Note though, that in accord with many other series (Record and McKeown, 1949; Ingalls, Pugh, and MacMahon, 1954; Coffey and Jessop, 1958; 
TABLE II

INCIDENCE OF ANENCEPHALIC STILLBIRTH BY PARITY (LEGITIMATE BIRTHS ONLY)

\begin{tabular}{|c|c|c|c|c|c|}
\hline \multicolumn{3}{|c|}{ Parity } & $\begin{array}{c}\text { Cases of } \\
\text { Anencephalus }\end{array}$ & $\begin{array}{c}\text { Total } \\
\text { Population }\end{array}$ & Rate $\pm \mathbf{S E}$ \\
\hline $\begin{array}{l}0 \\
1 \\
2 \\
3 \\
4 \\
5 \\
6+\end{array}$ & $\begin{array}{l}\ldots \\
\ldots \\
\ldots \\
\ldots \\
\cdots \\
\cdots\end{array}$ & 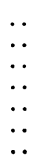 & $\begin{array}{r}1004 \\
684 \\
432 \\
278 \\
163 \\
87 \\
102\end{array}$ & $\begin{array}{r}380435 \\
316795 \\
188058 \\
97786 \\
49736 \\
25701 \\
29006\end{array}$ & $\begin{array}{l}2.64 \pm 0.08 \\
2.16 \pm 0.08 \\
2.30 \pm 0.11 \\
2.84 \pm 0.17 \\
3.28 \pm 0.26 \\
3.39 \pm 0.36 \\
3.52 \pm 0.35\end{array}$ \\
\hline \multicolumn{3}{|c|}{ Total recorded } & 2750 & 1087517 & $2.53 \pm 0.05$ \\
\hline
\end{tabular}

Searle, 1959; Betheras, 1962; Muffarij and Kilejian, 1963; Frézal et al., 1964; Carter, David, and Laurence, 1968; Naggan, 1971) there is a marked increase in the incidence with increasing parity from parity one until parity four when there appears to be some levelling out of the rate.

\section{Parental Ages}

Edwards's data indicated a high risk to infants of teenage mothers, lowest risk at ages 25-29 years and a rising incidence thereafter. The present data exhibit the same effect (Table III) which has been reported in some other series (Ingalls et al., 1954; Betheras, 1962; Hamersmaa, 1964; Carter et al., 1968; Rogers, 1969). Unfortunately it is not possible from the published data to assess the effects of parity and maternal age simultaneously, but a previous study indicated that in the United Kingdom the primiparity effect is more marked among the young mothers and the multiparity effect is chiefly found among the older women (Fedrick, 1970a).

Information on paternal age has been lacking from most studies. Analysis of the Scottish data showed the type of effect that one would expect

TABLE III

INCIDENCE OF STILLBIRTHS WITH ANENCEPHALUS

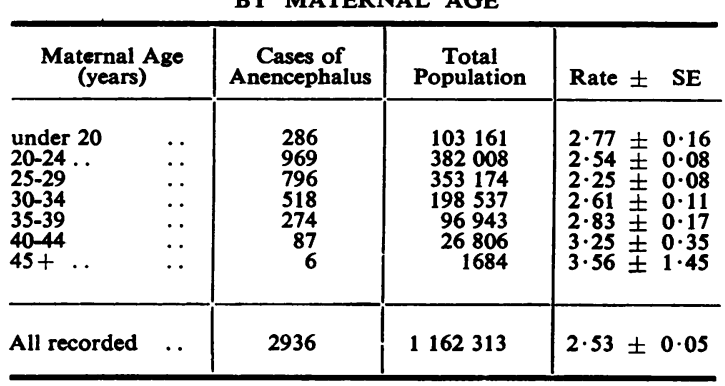

from the maternal age pattern, with lowest incidences between the ages of 25 and 34 years. Although the data did not permit a complex analysis taking maternal age and parity into account, there was little prima facie evidence to indicate that paternal age was of importance.

\section{SEAsonal Variation}

Edwards found, as had McKeown and Record (1951) previously, that there was a pronounced seasonal variation in the number of anencephalics delivered: the winter incidence being about a third greater than the summer incidence. The present data showed little variation, the winter incidence being only $6 \%$ greater than the summer.

The variation, such as there is, is not statistically significant whether using the method of Edwards (1961) of testing for cyclic trend or the nonparametric method of Hewitt et al. (1971).

\section{Secular Variation}

In an analysis of the yearly variation in the incidence of the lesion there are two aspects to consider: first, is there an overall trend, and secondly, can any particular years be considered to have more or fewer cases than would be expected by chance? From Fig. 3 it can be seen that the rate of anencephalus decreased during the period, the data being compatible with the equation:

$$
y=3 \cdot 392-0 \cdot 113 x
$$

where $y$ is the rate of anencephalus and $x$ is the number of years after 1961. (The standard error of the regression coefficient is 0.021 ; that is, the trend is highly significant: $t=5.4 ; \mathrm{df}=10 ; \mathrm{P}<0.001$ ). The numbers of cases expected, from this equation, to have occurred in each year have been calculated and there does appear to be significant variation $\left(\chi^{2}=20.8, P<0.05\right)$ with an excess of cases in 1961 and 1971 and a dearth in 1962.

Having established that there was an overall downward trend in incidence in Scotland throughout the 12-year period, let us examine the question of whether the fall is consistent within age, social class, and parity groups.

Table IV shows the change in incidence within groups. The reduction in incidence was marked in social classes III, IV, and V but was barely apparent in social classes I and II. Although the decrease was constant with parity there was marked variation with maternal age: the reduction among births to teenage women being such that in the second period of time the incidence in this age group was almost identical to the incidence among the births to women aged 20 to 34 years. 


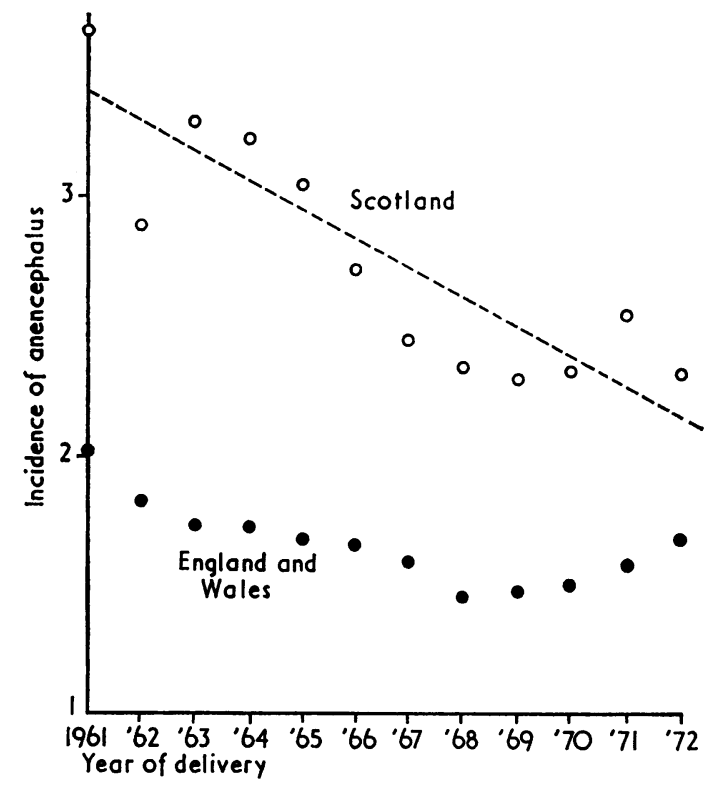

Fig. 3. Incidence of anencephalus by year of delivery from Reports of the Registrars General for Scotland and England and Wales.

TABLE IV

VARIATION IN INCIDENCE OF ANENCEPHALUS WITH VARIOUS PARAMETERS DURING TWO SIX-YEAR PERIODS

\begin{tabular}{|c|c|c|c|c|}
\hline \multirow{2}{*}{\multicolumn{2}{|c|}{ Variable }} & \multicolumn{3}{|c|}{ Rate } \\
\hline & & $1961-66$ & $1967-72$ & $\begin{array}{c}\text { Decrease } \\
(\%)\end{array}$ \\
\hline $\begin{array}{l}\text { Season of birth*† } \\
\text { January-March } \\
\text { April-June } \\
\text { July-September } \\
\text { October-December }\end{array}$ & $\begin{array}{l}.0 \\
\ddot{.}\end{array}$ & $\begin{array}{l}3 \cdot 52 \\
3 \cdot 03 \\
3 \cdot 34 \\
3 \cdot 42\end{array}$ & $\begin{array}{l}2 \cdot 64 \\
2 \cdot 58 \\
2 \cdot 49 \\
2 \cdot 59\end{array}$ & $\begin{array}{l}25 \\
15 \\
25 \\
24\end{array}$ \\
\hline 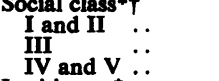 & .. & $\begin{array}{l}1.56 \\
3.24 \\
3.81\end{array}$ & $\begin{array}{l}1 \cdot 47 \\
2 \cdot 30 \\
3 \cdot 05\end{array}$ & $\begin{array}{r}6 \\
29 \\
20\end{array}$ \\
\hline $\begin{array}{l}\text { Legitimacy* } \\
\text { Legitimate } \\
\text { Illegitimate }\end{array}$ & .. & $\begin{array}{r}3 \cdot 15 \\
2.98\end{array}$ & $\begin{array}{l}2 \cdot 36 \\
2 \cdot 69\end{array}$ & $\begin{array}{l}25 \\
10\end{array}$ \\
\hline 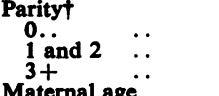 & . & $\begin{array}{l}2 \cdot 97 \\
2 \cdot 51 \\
3 \cdot 48\end{array}$ & $\begin{array}{l}2 \cdot 29 \\
1 \cdot 87 \\
2 \cdot 57\end{array}$ & $\begin{array}{l}23 \\
25 \\
26\end{array}$ \\
\hline $\begin{array}{c}\text { Maternal age } \\
\text { Under } 20 \\
200-34 \\
35+\end{array}$ & $\because$ & $\begin{array}{l}3.43 \\
2.75 \\
3.17\end{array}$ & $\begin{array}{l}2 \cdot 21 \\
2 \cdot 10 \\
2 \cdot 56\end{array}$ & $\begin{array}{l}36 \\
24 \\
19\end{array}$ \\
\hline All* & .. & $3 \cdot 14$ & $2 \cdot 39$ & 24 \\
\hline
\end{tabular}

* Live and stillbirth

+ Rate per 1000 legitimate births

Finally, there is some suggestion that there was a slight seasonal variation in the first six years which became barely perceptible in the later period. This is similar to the findings of Leck and Record (1966) for Birmingham and Elwood and Nevin (1973) in Belfast.

\section{Discussion}

The present study has repeated the finding of Edwards (1958) of marked geographical variation in the incidence of the lesion, but perhaps of more interest is the comparison of the incidences found in his study with those found at this later period of time. In Scotland as a whole, the population had decreased between the two census years of 1961 and 1971; the only areas in which there had been a slight increase being the far western highlands and the area around the Firth of Forth (Nissel and Lewis, 1974). The former area had a large increase in incidence, the latter a decrease. Thus it seems unlikely that the increase in rates in certain areas could be due to differential emigration of the 'fitter' members of the community.

In the Netherlands a marked geographical variation in the incidence of anencephalus was als@ found (Verstege, 1971). This was shown to be $\overrightarrow{0}$ significantly correlated with the softness of the $\sigma$ local water supply in accord with studies in the British Isles (Fedrick, 1970b; Lowe, Roberts, and Lloyd, 1971; Verstege, 1971). Nevertheless hè also found curious secular patterns, the incidence falling dramatically during the period 1951-68 in the rural areas but rising in the previously low incidence area of Zeeland. The author could find no explanation for this phenomenon.

The other changes of pattern are also of interest. The marked increase in incidence with low maternal age has almost vanished, but whereas formerly the incidence among illegitimate births was slightly lower than that among legitimate births, the reverse has now occurred. Overall in Scotland during the 12-year period the rate of illegitimate births increased from $5 \%$ of all births in the first six years to $8 \%$ during the period 1967-72.

The maternal age distribution has also varied during the period with the proportion of deliveries to women under 20 years increasing from $7 \cdot 7 \%$ to $10.4 \%$, whereas the proportion of mothers over 34 years decreased from $12 \cdot 2 \%$ to $9 \cdot 4 \%$. Simultaneously there was a decrease in the number of women being delivered who were of parity three or more, from $21 \%$ in the first six-year period to $16 \%$ in the second. In comparison the distribution of all births by social class has shown far less variation: the proportion of social classes IV and $\mathrm{V}$ has decreased from $29.9 \%$ to $28.4 \%$ and the 'upper' social classes increased from $15 \cdot 3 \%$ to $18 \cdot 4 \%$. 
From all these factors it is difficult to explain the changes in the incidence of the lesion. Diet has been suggested as being an important factor in anencephalus (Renwick, 1972; Knox, 1972; Fedrick, 1974) and it is conceivable that some of the variation shown could be so explained. For example, it could be that the dietary factor is one to which the newest generation of reproducing women has not become so addicted as her elder sister. This would account for the marked decline in incidence in the younger age groups. It is also feasible that the substance or a combination of substances was primarily consumed by the women in the lower social classes and that reduction in consumption would therefore only affect the incidence in those social classes.

Although many substances, including tea, processed peas and, possibly corned beef probably fit this pattern, it is impossible without further data from other areas to make other than wild surmises.

I am grateful to Dr J. A. Baldwin and Professor Sir Richard Doll for helpful criticism and advice and to Mrs Jean Lawrie for assiduously typing several versions of the manuscript.

Requests for reprints: Mrs J. Fedrick, Unit of Clinical Epidemiology, Department of the Regius Professor of Medicine, Oxford Regional Health Authority, Old Road, Headington, Oxford.

\section{REFERENCES}

Betheras, R. F. (1962). Obstetrical aspects of foetal hydrocephalus and anencephalus. Aust. J. Obstet. Gynaec., 2, 31.

Butler, N. R. and Alberman, E. D. (1969). Perinatal Problems: The Second Report of the 1958 British Perinatal Mortality Survey. Livingstone, Edinburgh and London.

Carter, C. O., David, P. A., and Laurence, K. M. (1968). A family study of major central nervous system malformations in South Wales. J. med. Genet., 5, 8.

CoffeY, V. P. and Jessop, W. J. E. (1958). A three years study of anencephaly in Dublin: a report on 181 cases. Irish J. med. Sci., 393, 391.

EDWARDS, J. H. (1958). Congenital malformations of the central nervous system in Scotland. Brit. J. prev. soc. Med., 12, 115.

- (1961). The recognition and estimation of cyclic trends. Ann. hum. Genet., 25, 83.

Elwood, J. H. (1970). Anencephalus in Belfast. Brit. J. prev. soc. Med., 24, 78.

(1972). Major central nervous system malformations notified in Northern Ireland 1964-68. Develop. Med. Child Neurol., 14, 731. and Nevin, N. C. (1973). Factors associated with anencephalus and spina bifida in Belfast, Brit. J. prev. soc. Med., 27, 73.

FEDRICK, J. (1970a). Anencephalus: variation with maternal age, parity, social class and region of England, Scotland and Wales. Ann. hum. Genet., 34, 31.

(1970b). Anencephalus and the local water supply. Nature (Lond.), 176, 177.

- (1974). Anencephalus and maternal tea drinking: evidence for a possible association. Proc. roy. Soc. Med., 67, 356.

Frézal, J., Kelley, J., Guillemot, M. L., and LAMY, M. (1964). Anencephaly in France. Amer. J. hum. Genet., $16,336$.

HamersmaA, K. (1964). Anencefalie in Rotterdam. Ned. T. Geneesk., 1081, 1109.

Hewtt, D., Milner, J., Csima, A., and Pakula, A. (1971). On Edwards' criterion of seasonality and a non-parametric alternative. Brit. J. prev. soc. Med., 25, 174.

Ingalls, T. H., Pugh, T. F., and Macmahon, B. (1954). Incidence of anencephalus, spina bifida and hydrocephalus related to birth rank and maternal age. Brit. J. prev. soc. Med., 8, 17.

KNox, E. G. (1972). Anencephalus and dietary intakes. Brit. J. prev. soc. Med., 26, 219.

LECK, I. and RECORD, R. G. (1966). Seasonal incidence of anencephaly. Brit. J. prev. soc. Med., $20,67$.

LOWE, C. R., RoberTS, C. J., and LLOYD, S. (1971). Malformations of the central nervous system and softness of local water supplies. Brit. med. J., 2, 357.

McKeown, T. and Record, R. G. (1951). Seasonal incidence of congenital malformations of the central nervous system. Lancet, 1, 192.

MuffariJ, I. K. and Kilejian, V. O. (1963). Anencephaly: an analysis of anencephalic births and a report of a case of repeated anencephaly. Obstet. and Gynec., 22, 657.

NaGgan, L. (1971). Anencephaly and spina bifida in Israel. Pediatrics. 47, 577.

Nissel, M. and LewIS, C. (1974). Social Trends No. 5. HMSO, London.

ReCord, R. G. and McKeown, T. (1949). Congenital malformations of the central nervous system. Brit. J. prev. soc. Med., 3, 183.

ReNwiCK, J. H. (1972). Hypothesis: anencephaly and spina bifida are usually preventable by avoidance of a specific but unidentified substance present in certain potato tubers. Brit. J. prev. soc. Med., 26, 67.

ROGERS, S. C. (1969). Epidemiology of stillbirths from congenital abnormalities in England and Wales 1961-66. Develop. Med. Child Neurol., 11, 617.

SEARLE, A. G. (1959). The incidence of anencephaly in a polytypic population. Ann. hum. Genet. 23, 279.

VeRSTEGE. J. C. W. (1971). Anencephalie in Nederlund 1951-1968. Central Bureau voor Statistiek, Staatsuitgeverij, The Hague. 